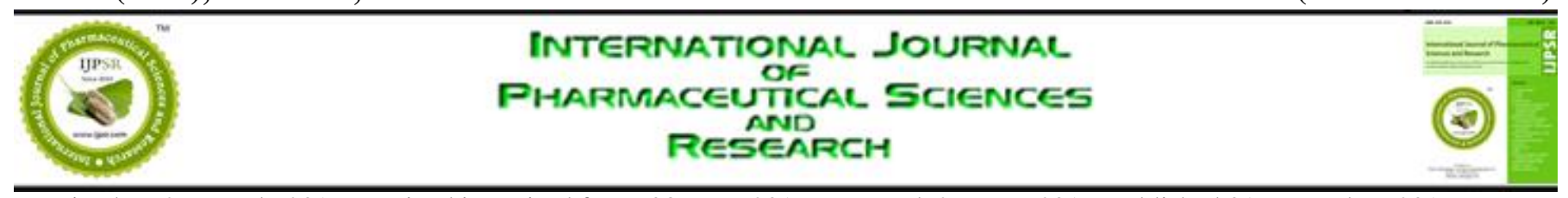

Received on 27 March, 2017; received in revised form, 03 June, 2017; accepted, 27 June, 2017; published 01 November, 2017

\title{
CHARACTERISTICS OF DIGESTION IN HIGH-PRODUCING COWS: DEPENDENCE ON THE FAT CONCENTRATION IN THE RATION DRY MATTER
}

Sergey Y. Smolentsev ${ }^{* 1}$, Lilia E. Matrosova ${ }^{2}$, Elena L. Matveeva ${ }^{2}$, Alla E. Ivanova ${ }^{2}$, Valentina P. Korosteleva $^{3}$, Alinya R. Nurgalieva ${ }^{3}$, Diana R. Sharafutdinova ${ }^{3}$ and Aigul Z. Karimova ${ }^{3}$

Agrarian Technology Institute ${ }^{1}$, Mari State University, Lenin Square 1, Yoshkar-Ola City - 424000, Russia.

Faculty of Service, Tourism and Food Technology ${ }^{2}$, Kazan Innovative University Namedafter V.G. Timiryasov, Moskovskayastreet 42, Kazan City - 420111, Russia.

Engineering and Technology Faculty ${ }^{3}$, Kazan Cooperative Institute (Branch) Russian University of Cooperation, N. Ershov Street 58, Kazan City - 420081, Russia.

Keywords:

Lipids, Ration, Cows,

Forestomachs, Microflora, Microfauna

Correspondence to Author:

Sergey Y. Smolentsev

Agrarian Technology Institute,

Mari State University, Lenin

Square 1, Yoshkar-Ola

City - 424000, Russia.

E-mail: Smolentsev82@mail.ru

\begin{abstract}
Lipid metabolism in animals has recently gained growing interest among researchers. Among organic compounds, it is only protein and nucleic acids that for a long time have remained in primary focus of research, though lipids are now known to be essential for the origin of life and development of organic forms. Metabolic processes are very active in the bodies of high-producing cows. Large amounts of energy and nutrients are utilized to synthesize milk; all body systems function intensely. Consequently, there are increased demands for adequate supply of energy and all nutrients including lipids. Insufficient or excessive intake of the latter leads to disruption of metabolism, lower productivity, and deterioration of animal health. At present, there is some controversy in the Russian and foreign literature in regard to on the optimal fat content in the dry matter of the rations of lactating cows, especially high-producing ones. Researchers recommend rather wide ranges of fat concentrations in the diets. The issue that remains insufficiently explored is the effect of various fat levels on ruminal digestion processes, the $\mathrm{pH}$ of the rumen contents, concentrations of volatile fatty acids in the rumen, activity of symbiotic microorganisms, the size and species composition of microbiota in different parts of the digestive tract, as well as the key indicators characterizing digestion in high-producing cows.
\end{abstract}

INTRODUCTION: Lipids is the term used to denote a large group of organic substances, diverse in their composition and functions, which contain long aliphatic chains with fat-like and other common physicochemical properties. These organic compounds widely occur naturally and are integral components of living cells, tissues and body fluids ${ }^{1}$.

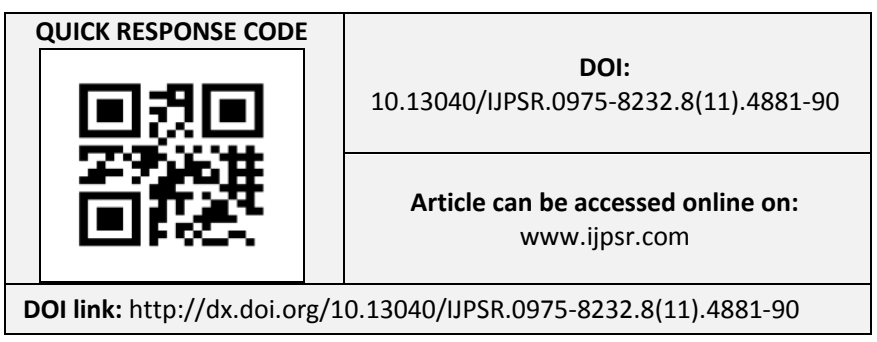

Lipid metabolism in the forestomachs is a complex process. It is carried out by the system feedmicroorganisms-macroorganism and, in principle, impacts substantially the nature of the intermediary lipid metabolism and the productivity of ruminants. From a physiological perspective, the fore stomachs constitute a single rumino-reticulum cavity where feed digestion occurs in the contents consisting of four fractions: bacteria, infusoria, rough feed residues, and acellular fluid.

However, regardless of the significant role of microbial fermentation in the lipid metabolism and transformation, it is the animal's organism with its neurohumoral regulation and adaptive-genetic 
specificity that performs the decisive function. Lipid metabolism takes place due to the interaction between feed particles, microflora, microfauna, and the host animal ${ }^{2}$. Digestion in the forestomachs of ruminant animals is quite a complicated process affected by a number of factors including the feeding level, in particular, the fat content of the diet. There is a lack of consistent data in the Russian and foreign literature relating to the effects of various sources and levels of dietary fat intake on the characteristics of metabolic processes in the cow's rumen.

The anatomical structure of the rumen and conditions therein fully meet the requirements for bacterial fermentation. Due to the good thermoregulatory capabilities of the cow's body, the temperature inside the rumen remains constant, with mean ruminal temperature being at about $39^{\circ} \mathrm{C}$. The saliva rich in carbonate and phosphate buffers ensures a stable $\mathrm{pH}$ environment and buffering system ${ }^{3}$. Steady nutrient supply to the rumen, accumulation of carbon dioxide, rapid binding of oxygen transported to the rumen with water ${ }^{4}$, as well as absorption of metabolites, etc. provide favourable conditions for the growth and development of anaerobic and optionally anaerobic microorganisms.

Microorganisms living in ruminants' forestomachs actively participate in the fermentation of feed nutrients and are themselves broken down in the subsequent parts of the digestive tract under the influence of enzymes and hydrochloric acid, with the resulting proteins, fats and carbohydrates being absorbed by the organism. Ruminal microbiota also contributes to the satisfaction of animal's needs for Vitamins B, C and $\mathrm{K}^{5,6}$.

It was found that rumen microorganisms are capable of transforming lipids from the foodstuffs, and those transformations determine the peculiarities of lipid metabolism in ruminants ${ }^{7}$. Most proteolytic bacteria isolated from the rumen of ruminant animals were in the shapes of bacilli or cocci and gave a positive reaction in the Gram stain test; instances of gram-negative bacteria were rare ${ }^{8}$. Cellulolytic bacteria were mainly gram-negative 9,10 . Therefore, the optimization of the cow's lipid intake allows directing the metabolism towards a more efficient energy and nutrient utilization for milk synthesis, as well as maximizing the quantity and quality of milk production. A series of studies have been carried out to investigate the effects of various fat concentrations in the rations of highproducing cows on the key characteristics of their ruminal digestion. Holstein cows with a high production potential were used for this research. All the animals were clinically healthy.

MATERIALS AND METHODS: To carry out the studies, three groups of cows (10 animals each) were made up in line with the method of counterpart pairs or a mini-herd. Mean difference in live weight and productivity of the cows from different groups did not exceed 5\%. On average, the cows had live weight of $600 \mathrm{~kg}$, daily milk yield of $27 \mathrm{~kg}$ with milk fat content of $3.29 \%$, productivity over the previous lactation of $6773 \mathrm{~kg}$, and the milk flow rate of $1.9-2.2 \mathrm{~kg} / \mathrm{min}$.

The liquid phase of ruminal digest a collected with the help of an orogastric tube was analysed in order to determine the concentration of hydrogen ions $(\mathrm{pH})$ by means of a universal ionometer; bacterial cellulolytic activity was estimated by V.A. Kaplan and E. S. Mosolova's technique; ammonia concentration was determined by the micro diffusion method in Conway's cups; the total volatile fatty acids was examined by steam distillation in Markham's apparatus followed by the titration of distillate yield. The separation of volatile fatty acids was performed by column chromatography; the total amount of lipids was established by extraction with diethyl ether in a Soxhlet apparatus; the total and residual nitrogen content was determined by Kjeldahl's method, protein nitrogen level was counted by computational method; the density and species composition of the infusorial fauna were examined by direct microscopy using a Fuchs-Rosenthal chamber and V. A. Dogel's determinant; the numbers of bacteria in the liquid phase of the contents of different parts of the gastrointestinal tract were counted by means of the microscopy method proposed by E. M. Foster.

The feeding of cows from the compared groups was implemented according to the research scheme at the premises of the "Azanovsky" breeding company. The rations were well-balanced in terms of the content of energy, nutrients and biologically 
active substances. The diets consisted of clover haylage, cereal hay, fodder beet, beet molasses, clover grass meal, sunflower meal, wheat bran and mixed feed. On average, over the period of the experiment, the specific weight of haylage was $30 \%$ and that of concentrated feed was $40 \%$ in the ration structure. Regardless of fat concentrations in the rations, one kilo of dry matter contained an average of 10 megajoules (MJ) of the metabolic energy. Cows from the control group were fed a diet with the fat concentration of $3.2 \%$ in conformity with the All-Russian detailed feeding regulations. The fat concentrations in the rations of cows from Group 2 and Group 3 were increased to $4.2 \%$ and $5.2 \%$ of the dry matter, respectively, by adding stabilized vegetable oil to the mixed feedstuff.
RESULTS OF RESEARCHES: Based on the zootechnical, biochemical, and hematological studies undertaken, it was established that the fat concentration of $3.2 \%$ in the ration dry matter was insufficient, the fat concentration of $4.2 \%$ was optimal, and the fat concentration of $5.2 \%$ was excessive. The animals from the experimental groups presented increased intensity and depth of the ruminal fermentation. The analysis of ruminal digestion parameters indicated that the latter were within normal physiological limits. However, in parallel with an increase in the fat content of the ration dry matter, a tendency towards a decrease in the concentration of hydrogen ions was observed (Table 1).

TABLE 1: CONCENTRATION AND RELATIVE PROPORTIONS OF VOLATILE FATTY ACIDS (VFAS); CELLULOLYTIC ACTIVITY OF BACTERIA IN THE COW'S RUMEN CONTENTS

\begin{tabular}{cccc}
\hline Indicators & \multicolumn{3}{c}{ Groups } \\
\cline { 2 - 4 } & I & II & III \\
\hline pH & $6.48 \pm 0.27$ & $6.33 \pm 0.01$ & $5.9 \pm 0.17$ \\
Cellulolytic activity of bacteria, \% & $17.69 \pm 0.59$ & $18.88 \pm 0.29$ & $17.97 \pm 0.24$ \\
Total VFA, mmol/1 & $97.23 \pm 1.91$ & $104.53 \pm 0.51 * *$ & $98.81 \pm 0.67$ \\
incl.: acetic acid, \% & $68.9 \pm 0.81$ & $71.59 \pm 0.84$ & $66.3 \pm 1.41$ \\
propionic acid, \% & $18.30 \pm 1.24$ & $16.10 \pm 0.99$ & $19.20 \pm 0.72$ \\
butyric acid, \% & $12.80 \pm 0.75$ & $12.31 \pm 1.22$ & $14.50 \pm 0.56$ \\
\hline
\end{tabular}

The tendency manifested itself in a shift of the $\mathrm{pH}$ value of the rumen fluid towards more oxidizing values by $2.32 \%$ in animals from Group 2 due to the acetic character of the fermentation processes as well as an increase in the production of acetate involved in lipid metabolism, especially in the milk fat synthesis.

Ruminal lipolysis occurs under the influence of rather active microbial lipases; the end products of lipid transformations are free high-molecular weight fatty acids and VFAs generated as a result of the fermentation of carbohydrates. Therefore, supplying the fat deficit in the diets of cows from Group 2 was found to positively impact the total VFA increasing it by $7.51 \%(\mathrm{P}<0.01)$ in animals from Group 2 and by $1.63 \%$ in animals from Group 3, which directly reflected the degree and profoundness of the transformation of nutrients from the feeds consumed.

Due to increased cellulolytic activity of bacteria, acetic acid content grew by $2.69 \%$ ( $\mathrm{P}<0.01$ ), and the propionic acid level decreased by $2.2 \%$.
Consequently, the ratio of acetic to propionic acid increased from 3.8:1 up to 4.5: 1 . The increase in the dietary fat level from 3.2 to $4.2 \%$ had, however, a negligible effect on the butyric acid content.

The excessive fat intake caused a minor decrease in the total VFA content (by 1.62\%) and a significant and verifiable decrease (by 2.6\%) in the acetic acid content. Increased production of propionic acid (by $0.9 \%$ ) and butyric acid (by $1.7 \%$ ) in the liquid phase of the rumen content was observed. These data give an indication that the excessive fat content in the diet inhibits acetic acid fermentation while stimulating propionic and butyric acid fermentation.

The growth of the fat content in the diets of cows from Group 2 was accompanied by an increase of $6.73 \%$ in the cellulolytic activity of the symbiotic microflora.

Nitrogen-containing substances in the rumen contents of ruminant animals are represented by microbial protein, non-decomposed feed protein, 
end and intermediate products of nitrogen metabolism. The concentration of nitrogenous substances in the rumen fluid is known to be directly dependent on the diet composition as well as certain feeding factors, for instance, various fat concentrations in the ration dry matter.
Indicators of nitrogen metabolism occurring in the rumen show that an increase in the dietary fat content leads to increased activity of bacteria which break down feed protein and synthesize microbial protein Table 2.

\begin{tabular}{cccc} 
TABLE 2: CONCENTRATIONS OF NITROGENOUS FRACTIONS IN THE RUMEN CONTENTS, g/l \\
\cline { 2 - 4 } Indicators & \multicolumn{3}{c}{ Groups } \\
\cline { 2 - 4 } & I & II & III \\
\hline Total nitrogen & $0.891 \pm 0.01$ & $0.952 \pm 0.01 *$ & $0.920 \pm 0.01$ \\
Non-protein nitrogen & $0.371 \pm 0.01$ & $0.377 \pm 0.005$ & $0.361 \pm 0.009$ \\
Protein nitrogen & $0.520 \pm 0.01$ & $0.574 \pm 0.006 *$ & $0.558 \pm 0.005 *$ \\
\hline
\end{tabular}

Thus, an increase in the dietary fat content of the dry matter to $4.2 \%$ was associated with an increase of $6.73 \%(\mathrm{P}<0.05)$ in the total nitrogen content in the rumen fluid as compared to Group 1. This indicates improved digestibility of feed protein Table 2 and occurs due to the transfer of highly soluble feed protein to the rumen fluid, as well as a result of synthetic processes in the rumen, including microbial protein production. Further increase in the fat concentration up to $5.2 \%$ led to a decrease in the total nitrogen in the rumen by $3.5 \%$ as compared to experimental Group 2, and was, however, higher by $3.14 \%$ than that in the control.

Having entered the rumen, nitrogen-containing compounds of protein and non-protein nature are degraded and subsequently deaminated. Accordingly, an increase of $1.62 \%$ in the level of non-protein nitrogen was recorded in the rumens of heifers from Group 2. Ruminal microflora utilizes non-protein nitrogen, ammonia in particular, for synthesizing protein. This determined a significant $(\mathrm{P}<0.05)$ increase of $10.39 \%$ in the protein nitrogen content in the rumens of cows from Group 3, as well as an increase by $7.31 \%$ in animals from Group 3. The results indicate higher activity of metabolic processes within the rumen.

The state of ruminal microfauna is usually characterized by its species composition and the number the infusoria. Since protozoa are very sensitive to environmental fluctuations, their amount and activity can serve as a basis for estimating the intensity and other characteristics of ruminal digestion, health status and the ration quality of the animals. Therefore, an attempt has been made to reveal the effects of various fat levels in cow's hay diet on the density and species composition of the infusorial fauna Table 3.

TABLE 3: DENSITY AND SPECIES COMPOSITION OF INFUSORIAL FAUNA IN THE COWS' RUMEN CONTENTS, THOUS.CELLS/ML

\begin{tabular}{cccc}
\hline Species of rumen & \multicolumn{3}{c}{ Groups } \\
protozoa & I & II & III \\
\cline { 2 - 4 } Entodinium & $183.20 \pm 4.27$ & $191.43 \pm 4.04$ & $184.05 \pm 7.70$ \\
Diplodinium & $57.45 \pm 2.80$ & $56.21 \pm 4.59$ & $53.57 \pm 5.17$ \\
Epidinium & $17.83 \pm 1.18$ & $18.21 \pm 1.93$ & $18.44 \pm 1.42$ \\
Ophryoscolex & $8.71 \pm 1.49$ & $7.9 \pm 1.33$ & $6.13 \pm 1.27$ \\
Isotricha & $8.62 \pm 0.60$ & $8.52 \pm 1.01$ & $7.58 \pm 0.59$ \\
Total & $275.82 \pm 3.96$ & $281.88 \pm 5.66$ & $268.26 \pm 5.51$ \\
\hline
\end{tabular}

Irrespective of the dietary fat level, the infusorial fauna in the rumen contents of cows from all groups was represented, on average, by the species of entodinium (87.8\%) and diplodinium (20.2\%). The results obtained are in agreement with the data available in literature sources. Thus, according to I. G. Pivnyak and B. V. Tarakanov (1982), protozoa of the entodiniums species mostly predominate in the rumen of ruminant animals and often constitute up to $90 \%$ or more of the overall infusorial population. In the case of the optimal fat level in cows' diets $(4.2 \%)$, the concentration of infusorial genera of the species of entodinium tended to increase (by $4.2 \%$ ), and so did the concentration of 
epidinium (by 2.1\%), which was paralleled by a decrease in the concentrations of the diplodinium (by 2.2\%) and ophryoscolex (by 9.7\%) concentrations. The excessive fat content in the diet was associated with an unverifiable reduction in the concentrations of ophryoscolex by $29.6 \%$, isotricha by $12.1 \%$, and diplodinium by $6.8 \%$. The excessive fat level did not have a significant effect on other species of infusoria. A number of studies on ruminal protozoa in ruminant animals have been carried out using mixed diets (hay, haylage, silage, root crops, and concentrated feedstuffs), which, according to some authors, ensure the most favorable conditions for the growth of protozoa (I. G. Pivnyak, B. V. Tarakanov, 1982).

An equally important group of microorganisms involved in the transformation of nutrients in the gastrointestinal tract of ruminants is represented by bacteria Table 4.

TABLE 4: BACTERIAIN COWS' RUMEN CONTENTS: COMPOSITION BY NUMBER, SHAPE AND STAINING RESULTS (100 billion/ml)

\begin{tabular}{|c|c|c|c|}
\hline \multirow[t]{2}{*}{ Indicators } & \multicolumn{3}{|c|}{ Groups } \\
\hline & I & II & III \\
\hline Total number & $21.76 \pm 2.18$ & $16.87 \pm 1.2$ & $16.92 \pm 0.68$ \\
\hline Incl.: Micrococci & $7.22 \pm 0.55$ & $7.36 \pm 0.86$ & $7.39 \pm 0.66$ \\
\hline Diplococci & $6.22 \pm 0.69$ & $4.89 \pm 0.39$ & $5.87 \pm 0.21$ \\
\hline Streptococci & $1.76 \pm 0.43$ & $1.03 \pm 0.24$ & $1.08 \pm 0.17$ \\
\hline Tetracocci & $0.01 \pm 0.01$ & $0.26 \pm 0.89$ & - \\
\hline Staphylococci & $1.61 \pm 0.39$ & $1.32 \pm 0.10$ & $1.24 \pm 0.16$ \\
\hline Bacilli & $4.92 \pm 0.51$ & $1.32 \pm 0.10$ & $1.24 \pm 0.16$ \\
\hline \multicolumn{4}{|c|}{ Gram-positive } \\
\hline Total number & $9.37 \pm 1.21$ & $5.54 \pm 0.35$ & $4.60 \pm 0.33$ \\
\hline Incl.: Micrococci & $3.24 \pm 0.33$ & $2.67 \pm 0.19$ & $2.40 \pm 0.34$ \\
\hline Diplococci & $2.79 \pm 0.40$ & $1.76 \pm 0.12$ & $1.63 \pm 0.01$ \\
\hline Streptococci & $0.73 \pm 0.32$ & $0.23 \pm 0.04$ & $0.07 \pm 0.01$ \\
\hline Tetracocci & - & $0.08 \pm 0.05$ & - \\
\hline Staphylococci & $0.41 \pm 0.19$ & $0.57 \pm 0.11$ & $0.31 \pm 0.13$ \\
\hline Bacilli & $2.19 \pm 0.32$ & $0.21 \pm 0.1$ & - \\
\hline \multicolumn{4}{|c|}{ Gram-negative } \\
\hline Total number & $12.39 \pm 1.14$ & $10.66 \pm 1.21$ & $12.32 \pm 0.48$ \\
\hline Incl.: Micrococci & $3.98 \pm 0.25$ & $4.68 \pm 0.73$ & $5.01 \pm 0.53$ \\
\hline Diplococci & $3.43 \pm 0.32$ & $3.12 \pm 0.28$ & $4.25 \pm 0.20$ \\
\hline Streptococci & $1.02 \pm 0.10$ & $0.80 \pm 0.23$ & $1.01 \pm 0.16$ \\
\hline Tetracocci & $0.01 \pm 0.01$ & $0.18 \pm 0.10$ & - \\
\hline Staphylococci & $1.19 \pm 0.25$ & $0.75 \pm 0.07$ & $0.81 \pm 0.10$ \\
\hline Bacilli & $2.73 \pm 0.39$ & $1.11 \pm 0.09$ & $1.24 \pm 0.16$ \\
\hline
\end{tabular}

Issues related to ruminal lipolysis in ruminants have not been explored adequately. In the course of our research into the effects of different fat concentrations in cows' diets on the number of bacterial numbers in the rumen fluid, it was found that with an increase in the fat content in the ration dry matter to $4.2 \%$ and $5.2 \%$, the total amount of bacteria in the ruminal fluid of cows from Group 2 and Group 3 decreased by $15.9 \%$ on average. As the fat content in the cows' diets increased, a significant and verifiable reduction in the total number of gram-positive bacteria occurred. With an increase in the fat content in the ration dry matter to $4.2 \%$, their number decreased 1.7 times, and when the fat level reduction to $5.2 \%$, the bacterial population decreased 2.0 times. Among gram-positive bacteria, streptococci demonstrated the most significant variations in numbers. In the case of the fat level of $4.2 \%$, their number decreased 3.2 times, and with that of $5.2 \%-10$ times; the number of bacilli reduced 2 times; the number of diplococcic decreased by $1.6-1.7$ times, micrococci - by 17.6 - 25.9\%; the concentration of staphylococci increased by $24.4 \%$ at the fat level of $4.2 \%$ and decreased by $24 \%$ at the fat level of $5.2 \%$.

The total number of gram-negative bacteria varied to a lesser degree as compared to gram-positive bacteria. With the dietary fat level of $4.2 \%$, the 
number of micrococci increased by $17.6 \%$, and that of tetracocci 18 time; the numbers of the other bacterial genera decreased significantly, in particular, by $9.0 \%$ with regard to diplococci, by $21.6 \%$ for streptococci, by $37.0 \%$ for staphylococci and by 2.5 times regarding bacilli.

In the case of the excessive fat content $(5.2 \%$ of the ration dry matter), the total gram-negative bacteria did not change, the concentration of micrococci increased by $25 \%$, that of diplococci increased by $23.9 \%$. Simultaneously, the number of staphylococci decreased by $31.9 \%$, and the number of bacilli went down 2.2 times. Tetracocci was not detected in the liquid phase of the rumen digesta at the fat concentrations of $4.2 \%$ and $5.2 \%$ of the ration dry matter.

The ratio of gram-positive bacteria to gramnegative ones was 0.75 at the dietary fat content of $3.2 \%$; at the fat level of $4.2 \%$ the ratio was 0.52 , and at the fat level of $5.2 \%$ it was 0.37 .

Thus, increased fat concentrations in the rations of lactating cows affected the reduction in the total amount of gram-positive and gram-negative bacteria and their relative ratio in the rumen fluid. As a result of the microbiological studies undertaken, data have been collected on the concentrations, shapes and staining test results with regard to bacteria obtained from the forestomach chyme of the digestive tract. The data suggest that various fat concentrations in the diet influence the fluctuations in the bacterial community.

In particular, the total number of bacteria in the liquid phase of the reticulum content increased by $47.0 \%$ with an increase in the fat content in cow's rations to $4.2 \%$, and by $43.5 \%$ with the fat level increase to $5.2 \%$. In parallel, the concentration of micrococci grew 2.5 times, that of diplococciby $17.5 \%$ and $39.2 \%$, that of staphylococci by $95.5 \%$ and $38.0 \%$, respectively. Variations in numbers of bacilli were insignificant. Tetracocci were not present at the fat content of $3.2 \%$; they were detected in the amount of 0.4 billion per $1 \mathrm{ml}$ at the fat level of $4.2 \%$, and were found to maintain this level at the $5.2 \%$ fat concentration in the diet. Based on Gram staining results, gram-negative bacteria predominated. Their totals in the cases of the optimal and excessive levels of dietary fat content increased almost equally by $44.4-39.2 \%$.
An increase in the fat content in the ration dry matter to $4.2 \%$ was accompanied by the growth of positively stained micrococci by $81.7 \%$; with an increase of the dietary fat content to $5.2 \%$ their number grew 1.3 times, that of staphylococci increased 2.1 and 2.0 times, respectively; diplococci increased by $40.6 \%$ and $36.2 \%$, respectively, and the number of bacilli grew by $17.9 \%$ and $4.5 \%$, respectively. It was only the dietary fat content of $3.2 \%$ at which streptococci were found in insignificant amount.

The concentration of gram-positive bacteria changed in a different manner under the influence of various fat levels in the rations. As the dietary fat content increased, the total number of grampositive bacteria grew by $71.6 \%$ and $68.7 \%$, the concentration of micrococci increased by $2.7 \%$ and 2.8 times, that of diplococci increased by $37.1 \%$ and $29.8 \%$, staphylococci increased 2.1 and 1.8 times; no significant fluctuations were observed in the numbers of bacilli. Tetracocci were not detected at any of the dietary fat levels under investigation.

In the case of the fat content of $3.2 \%$ in the ration dry matter, the ratio of gram-positive to gramnegative bacteria in the reticulum content was significantly lower than in the rumen fluid and accounted for 0.42 ; the ratio was approximately the same, namely 0.50 , at the fat level of $4.2 \%$, and significantly higher at the $5,2 \%$ fat level amounting to 0.51 .

The liquid phase of the omasum chyme contained more bacteria than that of the reticulum. Bacterial numbers howed more considerable variations when affected by increasing the fat levels in the diet of high-producing cows. With an increase in the dietary fat level from $3.2 \%$ to $4.2 \%$, the total number of bacteria increased by $15.0 \%$, and with the fat content raised to $5.2 \%$ the total decreased 1.8 times.

In the case of the optimal dietary fat content, the numbers of micrococci, tetracocci, and staphylococci increased by $38.3 \%, 3.7$ times and 2.2 times, respectively, while the numbers of diplococci, bacilli, and streptococci decreased by $6.7,7.5$, and $21.7 \%$, respectively. Excessive dietary fat content was only associated with the growing concentration of staphylococci which increased by $49.3 \%$. 
Tetracocci were no longer present. Concentrations of the other bacterial genera decreased significantly: by $26.0 \%$ in case of micrococci, 2.5 times for diplococci, 3.1 times for streptococci and 3.4 times in regard tobacilli.

Gram-positive bacteria of the omasum contents reacted to the changes in the fat content of cows' diets much less than gram-negative ones. Tetracocci were not detected in the liquid phase of the omasum contents of cows from all experimental groups. An increase in fat content in the ration dry matter from $3.2 \%$ to $4.2 \%$ had no significant effect on the total of gram-positive bacteria while contributing to an increase in the concentration of micrococci by $31.1 \%$ and that of staphylococci1.8 times, as well as promoting a reduction in the number of diplococci by $24.7 \%$, streptococci 2.2 times, and bacilliby $48.9 \%$.

The excessive fat content in the diet was accompanied by decreasing numbers of all grampositive bacteria with the exception of staphylococci.

Gram-negative bacteria are more sensitive to variations in the fat content in the diets. When the optimal fat level was provided $(4.2 \%)$, the total of gram-negative bacteria increased by $31.7 \%$; the numbers of micrococci increased by $43.6 \%$, tetracocci grew 3.7 times, staphylococci- by $39.0 \%$, and bacilli increased by $26.1 \%$. Diplococci and streptococci did not show significant fluctuations in numbers.

When the dietary fat content was elevated to $5.2 \%$, tetracocci were not found in the omasum contents; the total number of gram-negative bacteria decreased 1.8 times; the numbers of micrococci, diplococci, streptococci, and rod- shaped bacteria decreased 1.6, 2.9, 2.1, and 2.6 times, respectively, while the amount of staphylococci increased 1.6 times.

The ratio of gram-positive bacteria to gramnegative ones in the liquid phase of the omasum contents with regard to the studied fat levels in cows' rations was 0.86 : 0.65 and 0.76 , respectively.

The concentration of bacteria in the abomasum contents was almost the same as in the forestomachs. With an increase in the fat content in cow's rations from $3.2 \%$ to $4.2 \%$, the concentration decreased by approximately $21.9 \%$, and with the fat content increased to $5.2 \%$, bacterial population size decreased almost 2 times. The number of micrococci decreased by $19.2 \%$ and 1.9 times, respectively, streptococci decreased in numbers 2.9 and 7.8 times, respectively, and the concentration of bacilli decreased 1.4 and 2.8 times, respectively. In the case of the $4.2 \%$ fat level in the ration, the number of tetracocci was reduced 2.6 times; in the case of the $5.2 \%$ fat level in the diet tetracocci were not detected. With the optimal level of fat content $(4.2 \%)$ in the ration dry matter, the concentration of diplococci did not change significantly; the excessive fat content led to a decrease of 1.8 times in their concentration.

In the case of the dietary fat content of $4.2 \%$, the total amount of gram-positive bacteria in the abomasum chime was slightly elevated (by 14.7\%) due to a minor increase in the numbers of micrococci and diplococci that make up the main part of this group of bacteria. No presence of tetracocci was recorded for any of the studied levels of dietary fat content. The concentration of other bacteria in this group varied more. The totals of the other bacterial species of this group changed to a greater extent. Thus, the concentration of staphylococci increased 3.7 times and that of bacilli by $43.7 \%$, whereas the number of streptococci decreased 2.7 times. The dietary fat content of $5.2 \%$ resulted in a reduction in the concentrations of micrococci, diplococci and streptococci by $16.1 \%, 2.2$ times, and 15.7 times, respectively, as well as in the absence of bacilli and increasing the number of staphylococci 13.1 times.

A different effect was exerted by various fat concentrations in ration dry matter on the total number and relative ratios of gram-negative bacteria. With an increase in the fat content in the dry matter of cow's rations from $3.2 \%$ to $4.2 \%$, their total number decreased by $36.3 \%$, and with the increase of the fat content to $5.2 \%$ the number went down 2.1 times. The number of micrococci was reduced by $34.2 \%$ and 3.2 times, respectively, diplococci decreased by 14.2 and $39.1 \%$, respectively, streptococci decreased 2.8 and 6.8 times, respectively; tetracocci decreased 2.6 times and disappeared, respectively; the number of bacilli decreased 1.8 and 2.3 times, respectively. 
The concentration of staphylococci at the optimum level of fat content was reduced by $47.1 \%$, the excess fat content led to a decrease of $30.1 \%$ in their total number.

The ratio of gram-positive to gram-negative bacteria was 0.42 in the case of fat content of $3.2 \%$ in the ration dry matter, it was 0.75 at $4.2 \%$ fat level, and the ratio was 0.61 at the $5.2 \%$ fat level.

The chyme passing from the abomasum into the small intestine has an acidic reaction. When exposed to juices produced by the pancreas, intestinal walls and the bile which have an alkaline reaction, the chyme is neutralized and acquires a slightly alkaline reaction. These changes should affect the growth and activity, number and species composition of microorganisms. Effect of various fat concentrations in the rations should be manifest in a different manner as well.

The results of the studies aimed to explore this issue show, that the amount of bacteria in the chyme of the small intestine is much lower than bacterial numbers in the forestomachs and abomasum. The ratio of gram-positive to gramnegative bacteria changes significantly, and so does the composition in the groups; the effect produced by various dietary fat concentrations on bacteria remains approximately the same. With an increase in the fat content in the ration dry matter from $3.2 \%$ to $4.2 \%$, the total number of bacteria increased by $29.2 \%$ and with the increase of the fat content to $5.2 \%$, bacterial number increased by $42.8 \%$.

The concentrations of individual bacterial genera fluctuated in different ways when affected by increasing the fat content in the diet. Compensating for the fat deficiency contributed to an increase in the number of micrococci, diplococci and staphylococcus 1.8, 1.7 and 2.8 times, respectively, as well as to a decrease of 4.9 times in the number of streptococci, and absence of bacilli. The excessive fat content in the diet resulted in increasing the number of micrococci by $19.6 \%$ only and that of diplococcic by $65.0 \%$; amount of tetracocci and bacilli increased 4.4 and 15.3 times respectively; the amount of streptococci went down 2.3 times.

The changes in the fat content in the diets of cows made a relatively smaller impact on the group of gram-positive bacteria and a greater impact on the group of gram-negative bacteria in the chyme of the small intestine. An increase in the dietary fat content from 3.2 to $4.2 \%$ was not associated with any change in the total count of bacteria of the first group. The content of micrococci increased by $34.4 \%$; the number of diplococci remained constant; the number of streptococci was reduced 10.9 times; the amount of staphylococci increased 3.3 times; tetracocci and bacilli were not present. In case of the dietary fat content of $5.2 \%$, the total number of gram-positive bacteria decreased 2 times. The numbers of micrococci, diplococci and staphylococci reduced by $24.0 \%, 2.1$ times, and 1.8 times, respectively; the number of bacilli increased 2.4 times.

The totals and concentrations of the majority of gram-negative bacteria genera grow considerably as the dietary fat levels increase. The total amount of gram-negative bacteria grew 1.8 times at the fat content of $3.2 \%$ of the ration dry matter and 2.8 times at the dietary fat content of $5.2 \%$. The concentration of micrococci increased 2.4 and 1.8 times, respectively, that of diplococci elevated 2.1 and 3.8 times, respectively, tetracocci increased in number 1.2 and 3.6 times, and the population of staphylococci grew 2.3 and 3.8 times. At a fat concentration of $4.2 \%$ of the dry matter in the diet, the number of streptococci decreased 2.7 times, bacilli were not detected; and at the dietary fat content of $5.2 \%$, the concentration of streptococci was identical to that associated with the $3.2 \%$ dietary fat content; the number of bacilli increased 21.2 times.

The ratio of gram-positive to Gram-negative bacteria decreased significantly as the dietary fat content increased. At the $3.2 \%$ fat content the ratio was 1.51 , at that of $4.2 \%$ the ratio was 0.85 , and at the $5.2 \%$ fat concentration the ratio was 0.26 . The contents of the large intestine contain bacteria in the amount substantially exceeding the number of bacteria in the chyme of the small intestine. This is determined by various factors including the dose of fat that enters the body. When studying the effects of different fat concentrations in the diets of highproducing cows on the amount of bacteria in the contents of the large intestine, it was found that an increase in the fat content of the ration dry matter from $3.2 \%$ to $4.2 \%$ led to an increase of 1.8 times in the total number of bacteria being investigated. 
Simultaneously, the concentration of micrococci grew 2.8 times, diplococci-1.5 times, staphylococci - 3.4 times, and with regard to bacilli 1.9 times. The numbers of streptococci and tetracocci decreased by $33.5 \%$ and 2.2 times, respectively.

An increase in the dietary fat level to $5.2 \%$ made a significantly lower impact. The total number of bacteria increased by $18.9 \%$ only; the numbers of micrococci and staphylococci grew by $59.5 \%$ and 7.9 times, respectively, while the numbers of bacilli and streptococci decreased by $27.17 \%$ and 3.0 times, respectively. The concentrations of diplococci and tetracocci did not change significantly.

Variations of the dietary fat content had a relatively small effect on gram-positive bacteria. An increase in fat content in the ration to $4.2 \%$ led to a unverifiable increase of $15.6 \%$ in the total number of these bacteria; the increase of the fat content to $5.2 \%$ resulted in decreasing their amount by $10.9 \%$. Individual bacterial genera displayed greater fluctuations in terms of quantity than their total. The concentration of micrococci increased 2.1 and 1.6 times, respectively.

The number of diplococci decreased 1.4 and 2.0 times, that of streptococci decreased 2.2 and 3.9 times. The content of bacilli increased insignificantly under the impact of the moderate fat content in the diet and sharply decreases (2 times) when affected by the increased fat concentration in the diet.

The number of gram-negative bacteria varied within a very wide range under the influence of different levels of dietary fat content. As a result of increasing the dietary fat content from to $4.2 \%$, their total increased 2 times. The concentrations of micrococci and diplococci increased 4.0 and 3.7 times, respectively; those of staphylococci and bacilli increased 2.0 and 3.2 times, respectively.

The concentrations of streptococci and tetracocci decreased by $21.0 \%$ and 2.2 times, respectively. With the dietary fat content of $5.2 \%$, the fluctuations in the amount of gram-negative bacteria were less pronounced. Their total number increased 1.6 times; the numbers of micrococci, staphylococci, and bacilli increased 1.8, 3.4, and 1.6 times, respectively. In parallel, the number of streptococci was reduced 2.7 times.
The ratio of gram-positive to gram-negative bacteria in the contents of the large intestines was 1.45 in case of the insufficient fat content in the diets of high-producing cows; the ratio was 0.60 at the optimum fat level; the excessive dietary fat level was associated with the ratio of 0.80 .

CONCLUSION: Thus, the data given above suggest that microflora of the contents of each part of the gastrointestinal tract is distinguished by its unique response to various fat concentrations in the diets of high-producing cows. Different fat levels make a substantial impact on the numbers and relative ratios of bacteria, the effects being different in regard to each part of the digestive tract. Maximum positive effect on the number, composition and activity of microorganisms in the contents of the digestive tract is associated with the fat content of $4.2 \%$ in the ration dry matter, which shall be considered optimal. This dietary fat concentration should contribute to improved digestion and absorption of nutrients and biologically active substances from the feeds.

\section{ACKNOWLEDGEMENT: Nil.}

\section{CONFLICT OF INTEREST: Nil.}

\section{REFERENCES:}

1. Barbosa A and Siniossoglou S: Function of lipid dropletorganelle interactions in lipid homeostasis. Biochimica et Biophysica Acta (BBA) - Molecular Cell Research 2017; 1864(9): 1459-1468.

2. Göke $\mathrm{K}$ and Bunjes $\mathrm{H}$ : Drug solubility in lipid nanocarriers: Influence of lipid matrix and available interfacial area. International Journal of Pharmaceutics 2017; 529(1-2): 617-628.

3. Stepien KM., Stewart FJ and Hendriksz CJ: The factors affecting lipid profile in adult patients with Mucopolysaccharidosis. Molecular Genetics and Metabolism Reports 2017; 12: 35-40.

4. Svobodova B and Groschner K: Mechanisms of lipid regulation and lipid gating in TRPC channels. Cell Calcium 2016; 59(6): 271-279.

5. Liu Z, Logan A and Cocks B: Seasonal variation of polar lipid content in bovine milk. Food Chemistry 2017; 237: 865-869.

6. Semenov EI, Tremasov MY, Matrosova LE, Tarasova EY, Kryuchkova MA, Smolentsev SY and Korosteleva VP: Joint effect of the mycotoxins T-2 toxin, deoxynivalenol and zearalenone on the weaner pigs against a background of the infection load. Research Journal of Pharmaceutical, Biological and Chemical Sciences 2016; 7(1): 1860-1868.

7. Mosrnann TR: Definition according to profiles of lymphokine activities and secreted proteins. Immunology 2016; 136: 2348-2357.

8. Nagaoka I, Tamura $\mathrm{H}$ and Hirata $\mathrm{M}$ : An antimicrobial cathelicudin peptide, human CAP18/LL37, suppresses 
neutrophil apoptosis via the activation of formyl-peptide receptor-like 1 and P2X7. Immunology 2017; 176: 30443052.

9. Termeer $\mathrm{C}$, Hennies $\mathbf{J}$ and Voith $\mathrm{U}$ : Oligosaccharides of hyaluronan are potent activators of dendritic cells. Immunol. 2015; 165: 1863-1870.
10. Smolentsev SY, Holodova LV, Polikarpov IN, Matrosova LE, Matveeva EL, Ivanova AE and Korosteleva VP: The infuence of probiotic on the biochemical status of young pigs. Bali Medical Journal 2017; 6(2): 92-95.

How to cite this article:

Smolentsev SY, Matrosova LE, Matveeva EL, Ivanova AE, Korosteleva VP, Nurgalieva AR, Sharafutdinova DR and Karimova AZ: Characteristics of digestion in high-producing cows: dependence on the fat concentration in the ration dry matter. Int $J$ Pharm Sci Res 2018; 8(11): 4881-90.doi: 10.13040/IJPSR.0975-8232.8(11).4881-90.

All @ 2013 are reserved by International Journal of Pharmaceutical Sciences and Research. This Journal licensed under a Creative Commons Attribution-NonCommercial-ShareAlike 3.0 Unported License.

This article can be downloaded to ANDROID OS based mobile. Scan QR Code using Code/Bar Scanner from your mobile. (Scanners are available on Google Playstore) 